\title{
Optimal Water Allocation in Golden Triangle Energy Region-A case study of Ningxia District
}

\author{
Yiqing Zhang ${ }^{\mathrm{a}}$, Xiaoyan Liu ${ }^{\mathrm{b}, *}$ \\ a Synergy Innovation Center for Energy Economics of Shandong, School of Business \\ Administration, Shandong Institute of Business and Technology, Yantai, Shandong \\ 264005, P. R. China \\ ${ }^{\mathrm{b}}$ Business School, LuDong University, Yantai, Shandong 264025, P. R. China
}

*Corresponding author at Business School, LuDong University, Yantai, Shandong 264025, P. R. China.

E-mail address: lxy_800929@163.com 
Abstract: There are abundant coal, oil and natural gas resources in "Golden Triangle" energy region. Energy resources development, coal chemical industry, coal power and other industries play an important role in promoting regional economic growth, but facing the insufficient water supply. Under the condition of marginal equilibrium of water resources, the paper firstly analyzes the water utilization, and calculates the potential water-saving amount. Then, the paper constructs a cooperative game model and allocates the newly increased GDP by using the weight distribution method. Finally, the paper puts forward some policy suggestions to reduce the efficiency gap of water utilization among regions.

Key Words: Golden Triangle Energy Region; Water Resources; Optical allocation

\section{Introduction}

The optimal allocation of water resources is essentially based on certain constraints, and pursues multi-objective optimization such as economic, social, and ecological environments. Many domestic and foreign scholars have conducted extensive and in-depth research on watershed and urban water resources allocation(Babel et al., 2005; Chen et al., 2006; Keramatzadeh et al., 2011; Kucukmehmetoglu and Guldmann, 2004; Sun and Zeng, 2012; Wichelns, 2002). From the perspective of water resources allocation mechanism, some scholars believe that the combination of government control and market mechanism can complete the optimal allocation of water resources.(Chen et al., 2013; Zilberman and Schoengold, 2005); From the perspective of water allocation methods, there are mainly game models(Chen et al., 2006; Sun, 2014), multi-objective linear programming models(Hu et al., 2016; Li and Guo, 2014), large system decomposition models(Chen, 2006), neural network models(Chen, 2006; Fang et al., 2014; Liu et al., 2010; Sun, 2009), and etc. The representative research results in water allocation are as follows. Taking the Euphrates and Tigris rivers as examples, Kucukmehmetoglu and Guldmann (2004) built cooperative game models, and analyzed the international water allocation and conflicts in Turkey, Syria, and Iraq; Li and Guo (2014) constructed a multi-objective water resource optimization allocation model including economic, social and ecological benefits, and applied it to Minqin irrigation area in Gansu Province; Based on the large-scale system decomposition and coordination theory, Chen et al. (2006) constructed a multi-objective system optimization model of water allocation, and 
made a case study of water allocation in Guangzhou; Liu et al. (2010) constructed a BP neural network model for optimal water allocation in the saltwater invaded areas, and took the Pearl River Delta as an example for case analysis.

With the implementation of China's western development strategy ${ }^{1}$, the water shortage in Ningxia Autonomous Region has become a bottleneck restricting rapid economic development. Domestic scholars evaluated the carrying capacity of water resources in Ningxia Autonomous Region and explored the intrinsic dependence of water resources utilization and economic growth (Li, 2018; Ma, 2019; Wang, 2018; Zhao, 2014). Among them, Zhao (2017) used the principal component and factor analysis methods to comprehensively evaluate the water resources capacity of five cities in Ningxia, and obtained the water utilization index and classification standards in 2013; Tang (2019) constructed the security index system to evaluate the change trend of water resources security in Ningxia; Taking Ningxia region as an example, Cui (2018) constructed a VAR model of water utilization and economic growth, and explored the internal dependence of water utilization and economic growth by using co-integration, impulse response and variance decomposition methods.

Aiming at water shortage in Northwest China, especially in the "Golden Triangle" energy region, domestic scholars have studied the optimal water allocation from the perspective of interest conflicts between the central and local governments, the ecological and environmental constraints, and the financial support in energy resources development(Bai, 2007; Li, 2013). Zhang (2014) analyzed the water resources in NingDong Energy and Chemical Industry Base, and proposed the ways to solve the water shortage, such as the "open source and reduce expenditure" water allocation scheme; Zhang (2010a) analyzed the water replacement and trans-regional water rights transfer between Ningdong and Zhangye districts in Gansu Province, and preliminarily explored the guarantee mechanism of water resource in the "Golden Triangle" energy region; Cheng (2011) analyzed the water shortage in the "Golden Triangle" energy region, focused on throttling, and put forward all-round water conservation in industry, agriculture, life and ecology; In order to allocate the water resources in the Northwest, Feng (2010) put forward policy recommendations for rationally setting water prices, total water consumption, and pollution control.

\footnotetext{
1 The scope of the western development includes 12 provinces, autonomous regions and municipalities, including Chongqing, Sichuan, Guizhou, Yunnan, Tibet Autonomous Region, Shaanxi, Gansu, Qinghai, Ningxia Hui Autonomous Region, Xinjiang Uygur Autonomous Region, Inner Mongolia Autonomous Region, and Guangxi Zhuang Autonomous Region, covering an area of 6.85 million square kilometers, accounting for $71.4 \%$ of the Country.
} 
Different from the above perspectives, this study takes Ningxia Autonomous Region as an example, and focuses on optimal water allocation in the "Golden Triangle" energy region. Aiming at the scarcity of water resources and large differences in water utilization efficiency among regions, this study, based on in-depth analysis of water consumption per GDP and industrial development, puts forward the system idea of optimizing water allocation and maximizing water utilization efficiency among regions, and gives policy recommendations to guarantee the water use in industries.

\section{Theory of optimal allocation of water resources}

In order to simplify the analysis of optimal water allocation, it is assumed that the goal of water use in different regions is to maximize the benefits of water. The GDP of different regions is expressed by $Y$, Water consumption of different regions is represented by WW.

Assuming that different regions take water resources as an input factor and satisfy the condition of Cobb-Douglas function, the GDP of different regions can be expressed as: $Y=f(A, K, L, W W)=A K^{\alpha} L^{\beta} W W^{r}$ Among them, Y represents the GDP; $\mathrm{A}, \mathrm{K}$, and $\mathrm{L}$ represent the technology, capital and labor respectively; $\alpha, \beta, \mathrm{r}$ are the GDP elasticity coefficients of capital, labor and water respectively. The marginal revenue of water utilization can be expressed as:

$$
M P_{w}=\partial f / \partial W W=r A K^{\alpha} L^{\beta} W W^{r-1}
$$

It is easy to draw the necessary conditions for optimal water allocation of different regions: the marginal benefits of water utilization among regions are the same, and equal to the unit cost of water resource. According to the above-mentioned ideas of optimal water allocation, the optimal water allocation determines the water flow direction and quantity, based on the marginal benefits of water utilization, and judge the water allocation effect by the water surplus or shortage under the conditions of equal marginal output among regions.

The optimal allocation of water resources can be achieved by constructing a cooperative game model. First, the GDP of water utilization are compared among regions under different water configurations; Second, the distributable profits "out-of-system" should be found, which satisfy the greatest gains among regions. Under the optimal water allocation, the water consumption among regions, which is the cooperative game solution, can be obtained through the weight distribution method. 
The calculation idea is as follows: Under the optimal water allocation system, the current benefit of water utilization among regions is expressed by $c_{i}$, the new benefit of water utilization among regions is expressed by $x_{i}$ after the weight distribution method, and the regions is expressed by $\mathrm{i}=1,2, \ldots, \mathrm{n}$, then under the cooperative game model, the new benefit among regions is expressed as: $x_{i}=c_{i}+\Delta N E T^{*} c_{i} / \sum_{i=1}^{n} c_{i}$

Among them, $\triangle$ NET is the difference between the total benefits, which is the “out-of-system profits" under water allocation schemes. Water supply in the "Golden Triangle" energy region is restricted by many constraints, which is the premise of optimal water allocation, including regional water balance constraint, per capita minimum domestic water constraint, per capita minimum food security constraint, regional ecological environment constraint. According to the principle of market efficiency, the water allocation among regions not only realizes the publicity of water resources, ensuring the overall water balance, ecological environment and domestic water consumption of residents, but also meets the economic scarcity of water resources. Application framework of regional water allocation is shown in Figure 1.

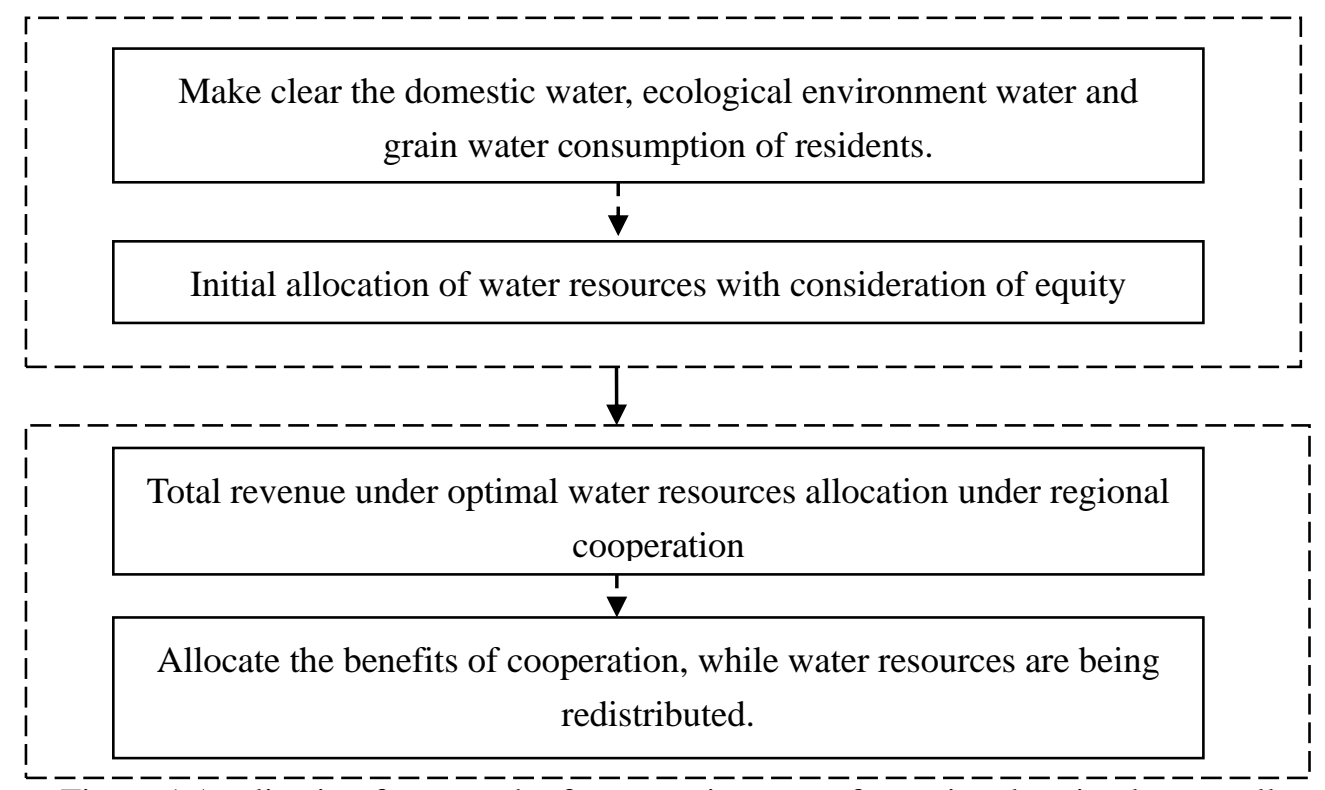

Figure 1 Application framework of cooperative game for regional optimal water allocation.

\section{An Empirical Study on Optimal Water Allocation in Ningxia District}

\subsection{Current water resources allocation in Ningxia}

The energy "Golden Triangle" Ningxia district is located in the north of Ningxia Province, covering an area of $80 \%$ of the total area. Ningxia district is located in a severely water-scarce area of western China with little rainfall and huge evaporation. The annual average precipitation is $240 \mathrm{~mm}$ and the evaporation is $1329 \mathrm{~mm}$; The 
Ningdong district mainly relies on the Yellow River for water diversion. The water resources in Ningdong district is $\mathbf{5 7 0}$ million cubic meters, accounting for only $\mathbf{4 9 \%}$ of the total area, while the population accounts for $78.2 \%$ of the region, where the per capita water resources is only 118 cubic meters. The water resources available in Ningdong district is 3.853 billion cubic meters, including 3.703 billion cubic meters available in the Yellow River, and 150 million cubic meters of groundwater resources available in local areas.

As a resource-rich region, Ningxia's energy chemical industry plays an important role in economic and social development. Among them, Ningdong district is rich in coal resources, and is one of the 14 national large-scale coal bases of 100 million tons, which are also the national large-scale coal power base and modern coal chemical industry demonstration areas. As coal-based energy industries consume a lot of water resources, with the development of coal-based energy industries, the water supply of Yellow River in Ningdong areas is increasingly tight, which has become an important factor restricting the energy resources development. On the one hand, Ningdong belongs to the region of water shortage, and the water supply is insufficient; On the other hand, there also exists the problems in Ningdong district, such as irrational water utilization structure and large gap in regional water utilization efficiency.

Therefore, on the basis of meeting the needs of ecological water, rural people, livestock and urban domestic water, optimizing the water allocation in the "Golden Triangle" of energy in Ningxia and ensuring the economic development of Ningxia has become a major problem to be solved. Therefore, on the basis of meeting ecological water, rural people, livestock, and urban domestic water consumption, water resources allocation in the "Golden Triangle" Ningxia District to ensure economic development in Ningxia has become a major issue to be urgently solved.

As can be seen from Figure 2, from 2009 to 2018, the water consumption per 10,000 Yuan of GDP among regions continued to decline. Among them, in 2018, the water consumption per 10000 Yuan of GDP in Guyuan city and Yinchuan city was 37 cubic meters and 56 cubic meters respectively, while that in Wuzhong city, Zhongwei city and Shizuishan city was very high, with 202 cubic meters, 179 cubic meters and 94 cubic meters respectively. It can be seen that there are great differences in water utilization efficiency among regions ${ }^{2}$. Therefore, on the premise that the total amount

\footnotetext{
2 According to the 2009-2018 Water Resources Bulletin issued by the Statistics Bureau of Ningxia Autonomous Region, the water consumption per 10,000 Yuan of GDP is calculated for Yinchuan city, Shizuishan city, Wuzhong city, Guyuan city, and Zhongwei city in Ningxia Province.
} 
of water supply in Ningdong district is fixed, it is urgent to allocate limited water resources among regions and pursue the maximum benefit of water utilization. Aiming at water utilization efficiency among regions, it is urgent to formulate differentiated water policies and implement the paid transfer of water rights, which is the fundamental way to ensure water utilization in energy development and chemical industries in Ningdong in the long run.

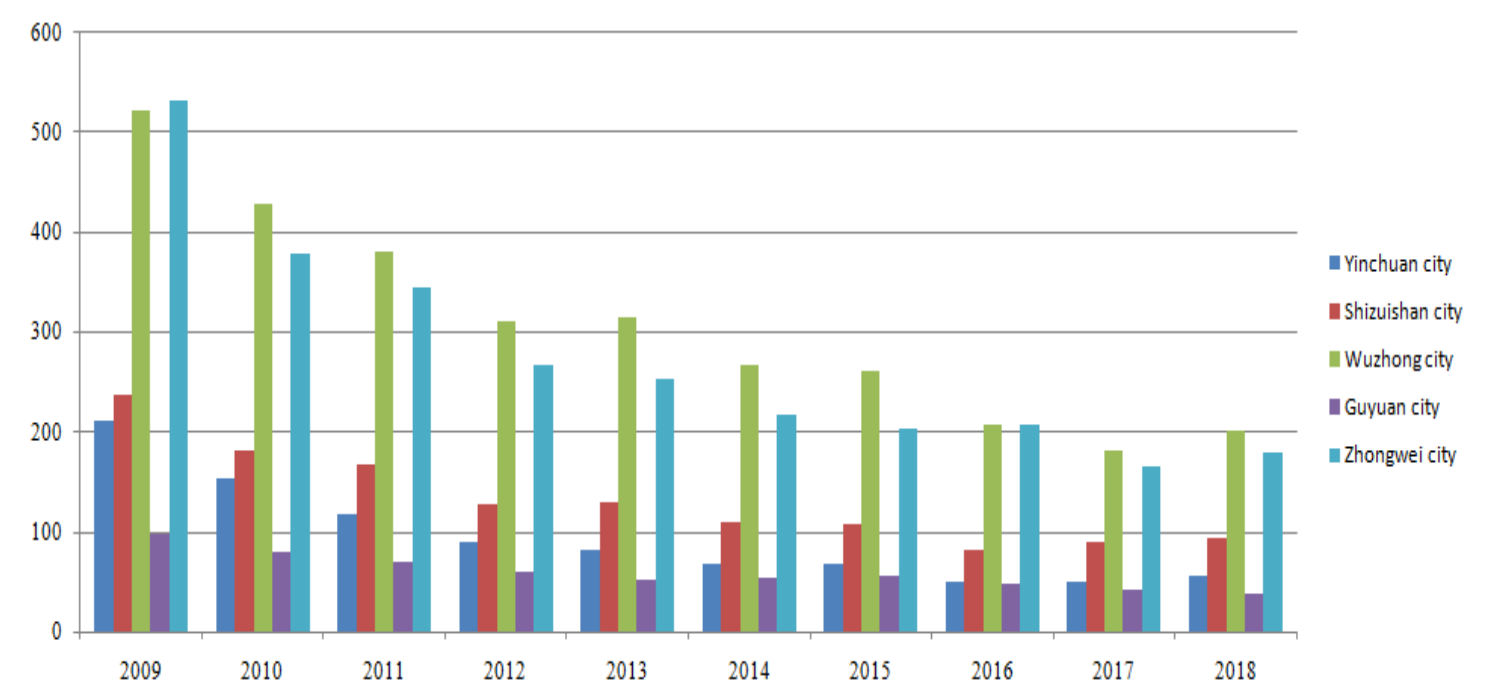

Figure 2 Water consumption per 10000 Yuan in Ningxia during 2009-2018.(Unit: Cubic meters /10000 Yuan)

\subsection{Optimal allocation and calculation of water resources in Ningxia}

The basic idea of optimal water allocation is to determine the average benefits of water utilization among regions and seek the allocation scheme of maximizing the water utilization benefits. According to the analysis in third part, it is learned that Wuzhong city, Zhongwei city and Shizuishan city in Ningxia district of the Energy Golden Triangle have lower water utilization benefits, while Guyuan City and Yinchuan city have higher water utilization benefits. Given other factors, the rational water allocation among regions can maximize the total water utilization benefits.

\section{(1)Marginal Water Consumption per 10,000 Yuan by Region}

The marginal water output refers to the GDP output (Unit: 10000 Yuan) increased by one unit input of water (Unit: ton) on the premise that other input factors are unchanged. The calculation formula is as follows:

$$
M P_{i}=\frac{\Delta G D P_{i}}{\Delta W_{i}}=\frac{G D P_{i(t)}-G D P_{i(t-1)}}{W_{i(t)}-W_{i(t-1)}}
$$


i represents different regions; GDP represents the GDP of the region; W represents the water consumption; $t$ represents the current year; $t-1$ represents the previous year. According to the above formula, the average benefit of water utilization in different regions of Ningxia in 2018 is calculated and sorted. The results are shown in Figure 3.

Water consumption per 10000 yuan of GDP in Ningxia(Unit: Cubic meter/10000 Yuan )

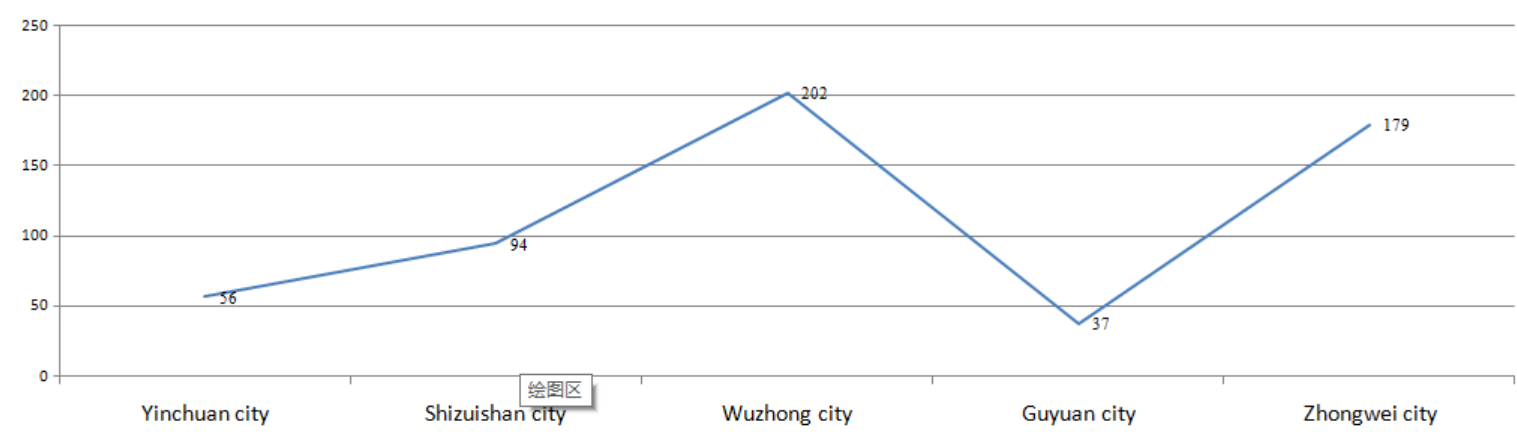

Figure 3 Cities' water resources average output of Ningxia in $2018^{3}$.

\section{(2)Water Savings in Different Regions under the Condition of Marginal}

\section{Output Equilibrium}

The core assumption of optimal water allocation is that the marginal output of water utilization among regions is the same. Therefore, the marginal water output in the highest region is taken as the standard, and the water savings in different regions are calculated under the same marginal water output.

Under the constraint of marginal water output in the highest region, if the GDP of other regions is kept constant, the water utilization must be reduced accordingly. The difference of historical water minus the water with equal marginal output is the water amount that are shifted from regions with low marginal water output to regions with high marginal water output. Based on the average output of water resources in Guyuan city, Ningxia District, the "Energy Golden Triangle" in 2018, the potential water surplus in other regions is calculated, and the calculation results are shown in Table 1.

Table 1 Cities' water surplus under the condition of average output equilibrium (unit: billion cubic meters)

\begin{tabular}{|c|c|}
\hline Yinchuan city & 2.3641 \\
\hline Shizuishan city & 3.1362 \\
\hline Wuzhong city & 8.0858 \\
\hline Guyuan city & 0.0000 \\
\hline Zhongwei city & 5.1644 \\
\hline
\end{tabular}

${ }^{3}$ In order to simplify the treatment, the regional water consumption per 10,000 Yuan GDP is used instead of the marginal water consumption per 10,000 Yuan of GDP. 
It is calculated that the water consumption per 10,000 Yuan of GDP in Guyuan city, Ningxia District is 37 cubic meters in 2018. Taking the water consumption per 10,000 Yuan in Guyuan city as the equilibrium standard, other regions will generate different water surplus. Among them, the potential water saving of Wuzhong city is 8085.8 million cubic meters. Zhongwei city, Shizuishan city and Yinchuan city also have a large potential water surplus.

With the increase of water consumption in Wuzhong city, the marginal water output decreases gradually, when the marginal water output is equal to that in the next highest region, the water allocation changes. Regional potential water surplus is the basis for optimal water allocation among regions. In order to achieve the same marginal water output in Wuzhong city as that in other regions, it needs the perfect water resources system, mature water rights market and efficient water-saving technologies ${ }^{4}$.

(3)Newly Allocated Output of Each Region under Optimal Water Allocation

According to the analysis of Figure 1 and Table 1, there is a space for optimal water allocation of each region in Ningxia Province. The cooperative game model is constructed to reasonably allocate the potential water surplus, and allocate the newly increased GDP through the weight distribution method ${ }^{5}$. According to the cumulative potential water surplus and average water output in Guyuan city, we calculate the potential maximum benefits that can be achieved, and then allocate the newly added benefits by using the weight distribution method.

According to table 1, the maximum water saving amount of the above industries in Ningxia is 1875.05 million cubic meters in 2018. According to the average GDP output of water in Guyuan City in 2018, which is the 270.2703 Yuan/cubic meter, the maximum potential GDP of Ningxia can be added by 50.677027 billion Yuan under the optimal allocation of water resources ${ }^{6}$.

Taking Guyuan city as an example, the GDP is 3.0514 billion Yuan in 2018, and the water consumption accounts for $3.8042 \%$ of the total water consumption in Ningxia region (The water consumption of Guyuan city is 112.9 million cubic meters,

\footnotetext{
${ }^{4}$ In reality, due to various factors, it is difficult for each region to achieve the same GDP of water consumption in various industries.

${ }^{5}$ The net income in different water allocation schemes is distributed by using the weight distribution method. The weight coefficient of each region is the proportion of initial water consumption in the total water consumption. ${ }^{6}$ On the premise of not influencing the conclusion, the paper assumes that the input factors such as capital and labor is not limited, water resources is the only factor restricting the GDP, and the marginal benefit of water remains unchanged with water consumption. The average GDP of water is used to replace the marginal GDP of water.
} 
and the total water consumption of Ningxia is 2967.8 million cubic meters in 2018). Under the optimal water allocation, the newly added GDP of Guyuan city is the product of the proportion of water consumption and the potential GDP of Ningxia $(50.677027$ billion Yuan * $0.0038042=1.9278$ billion Yuan); The GDP under the water optimal allocation is the actual GDP plus the GDP added by the water allocation of Guyuan city in 2018 (305.14 + $192.78=4.9792$ billion Yuan); The GDP growth rate is the potential GDP divided by the actual GDP of Guyuan city $(192.78 / 305.14=$ $63.18 \%$ ). The calculation results are shown in Table 2.

Table 2 the newly added GDP and its growth rate under different water allocation in NingXia region

(unit: billion cubic meters)

\begin{tabular}{|c|c|l|l|l|}
\hline Main District & $\begin{array}{l}\text { GDP of regions under } \\
\text { current water } \\
\text { allocation(billion Yuan) }\end{array}$ & $\begin{array}{l}\text { Newly added GDP in } \\
\text { regions under the optimal } \\
\text { water allocation(billion } \\
\text { Yuan) }\end{array}$ & $\begin{array}{l}\text { Total GDP in regions under } \\
\text { the optimal water } \\
\text { allocation(billion Yuan) }\end{array}$ & $\begin{array}{l}\text { Growth rate by } \\
\text { region in } \\
\text { Ningxia (\%) }\end{array}$ \\
\hline Yinchuan city & 12.4429 & 11.8983 & 24.3412 & $95.62 \%$ \\
\hline Shizuishan city & 5.5021 & 8.8315 & 14.3336 & $160.51 \%$ \\
\hline Wuzhong city & 4.9005 & 16.9032 & 21.8037 & $344.93 \%$ \\
\hline Guyuan city & 3.0514 & 1.9278 & 4.9792 & $63.18 \%$ \\
\hline Zhongwei city & 3.6369 & 11.1162 & 14.7531 & $305.65 \%$ \\
\hline
\end{tabular}

It can be seen from Table 2 that after the water optimal allocation, the GDP of each region increases significantly, that is, the Pareto improvement of water utilization among regions has been achieved. Among them, Wuzhong city, Zhongwei city and Shizuishan city have a larger GDP growth rate, with 3.45 times, 3.06 times and 1.61 times respectively. The reason is that the newly added GDP is allocated by using the weight distribution method, and Wuzhong city, Zhongwei city and Shizuishan city transfer a larger amount of water; In addition, the newly added GDP of Yinchuan city and Guyuan city are 0.96 times and 0.63 times respectively.

Although the above-mentioned water optimization arrangement in Ningxia district is only a theoretical water allocation scheme, it gives a quantitative reference for water allocation, providing a calculation and analysis basis for the reasonable and effective water allocation scheme.

\section{Conclusions and policy recommendations}

From an economic point of view, the total amount of water in the "Energy Golden Triangle" is scarce, and the supply of water is restricted by many conditions. At the same time, the rapid economic development in the "Energy Golden Triangle" is 
inseparable from energy resources, especially in the extremely water deficient areas such as Ningdong region. The theoretical and empirical analysis shows that on the premise of strict constraints, it is necessary to implement the most strict water resource management policy to allocate water in Ningxia district. The water supply in Guyuan city and other regions should be appropriately increased, and the water supply in Wuzhong city, Zhongwei city and Shizuishan city should be reduced, in order to get the equal benefit of water utilization among regions, and maximize the total benefit of water utilization.

The most strict water management policy should be carried out in the "Energy Golden Triangle" to allocate water scientifically. Industrial upgrading should be promoted by water conservation and protection, and transformation of economic development mode should be promoted by the mode transformation of water utilization, so as to ensure the water consumption of energy and chemical industries. In the design of optimal water allocation, the total water balance, basic domestic and ecological environment water as "hard constraints" should be firstly met, so that the water can be allocated to agriculture, secondary industries and tertiary industries according to the principle of market efficiency. Therefore the water optimization can ensure the publicity of water resources(Zhang, 2010b). At the macro level, the water authorities in "Energy Golden Triangle" should formulate water price and water quota of classified industries as soon as possible, and meanwhile, the authorities should issue relevant policies to realize the water rights replacement among industries. The policy recommendations are as follows:

(1) In order to ensure the water demand of key industries such as coal resource development, coal chemical and power industries in the "Energy Golden Triangle", we should focus on cultivating and developing the driving role of such industries in regional economic development. Such industries can be considered to give priority to the water supply in the way of low price and high quota, encouraging its rapid development, and maximizing the economic output with limited water consumption.

(2) For the agricultural sectors such as planting, breeding and fishery, it has the characteristics of high water consumption, little supporting role, and relatively slow growth rate, which belongs to the restricted industries, so we should adopt the strategy of low water quota and high water price; Water rights trading can also be used to transfer the water to industries with strong industrial support and large water demand, and industrial transfer should be made at an appropriate time. 


\section{Reference:}

Babel, M., Gupta, A.D., Nayak, D., 2005. A model for optimal allocation of water to competing demands. Water resources management 19, 693-712.

Bai, Y., 2007. Water Right Conversion and Water Saving Society Construction in Ordos City. China Water Resources 19, 45-46.

Chen, N.L., YuePeng; Xu,ChenGuang, 2006. Optimal deployment of water resources based on Multi_Objective Genetic Algorithm. Journal of hydraulic engineering 37, 308-313.

Chen, X., Chen, Y., Lai, G., Zeng, C., 2006. Optimal allocation of water resources in Guangzhou City, South China. Journal of Environmental Science and Health, Part A 41, 1405-1419.

Chen, Z., Wang, H., Qi, X., 2013. Pricing and water resource allocation scheme for the south-to-north water diversion project in China. Water resources management 27, 1457-1472.

Cheng, X.B.Z., ShuLing; Chen QingWei, 2011. Discussion on water resources management in the Golden Triangle area of China's energy chemical industry. Chinese Journal of Water Resources, 20-22.

Cui, Y.W., Ran, 2018. Study on the R elationship between Water $R$ esources Utilization and Economic Growth in Arid Region-Taking Ningxia as An Example. JOURNALOF HIT (SOCIAL SCIENCES EDITION) 20, 135-140.

Fang, G.H., Yin, Q.Q., Huang, X.F., Xu, S., 2014. Multi-objective optimal allocation for regional water and land resources, Applied Mechanics and Materials. Trans Tech Publ, pp. 58-64.

Feng, D.T., YanGuo; Zhang,Zhuo, 2010. The current situation, problems and suggestions of water-saving society construction in Northwest China. South To North Water Transfers and Water Science\&Technology, 92-94.

Hu, Z., Chen, Y., Yao, L., Wei, C., Li, C., 2016. Optimal allocation of regional water resources: From a perspective of equity-efficiency tradeoff. Resources, Conservation and Recycling 109, 102-113.

Keramatzadeh, A., Chizari, A., Moore, R., 2011. Economic optimal allocation of agriculture water: mathematical programming approach.

Kucukmehmetoglu, M., Guldmann, J.-M., 2004. International water resources allocation and conflicts: the case of the Euphrates and Tigris. Environment and Planning A 36, 783-801.

Li, M., Guo, P., 2014. A multi-objective optimal allocation model for irrigation water resources under multiple uncertainties. Applied mathematical modelling 38, 4897-4911.

Li, S.L., Wangcheng; Li,Chen; Dong, Yaping; Zhao, Yan; Wang, Xing, 2018. Analysis of Factors Affecting Water Resources Ecological Footprint of Ningxia Based on LMDI

Method. Anhui Agri.Sci.Bull 24, 84-87.

Li, S.W., BingLiang, 2013. Eco-hydrological Regionalization and Water Resources Development and Utilization Strategy in Ningxia. Yellow River, 68-70.

Liu, D., Chen, X., Lou, Z., 2010. A model for the optimal allocation of water resources in a saltwater intrusion area: a case study in Pearl River Delta in China. Water resources management 24, 63.

Ma, J.Y., YanZhong; Yang,Xue, 2019. Current Situation and Evaluation of Water Resource Bearing Capacity in Ningxia. Ningxia Engineering Technology 18, 179-182.

Sun, D.W., HuiMin; Yu,Jing, 2014. Study on Optimal Allocation of Water Resources in Basin Based on Cooperative Game Under Fuzzy Coalition. China Population, Resources and Environment 24, 153-158. 
Sun, W., Zeng, Z.J., 2012. City optimal allocation of water resources research based on sustainable development, Advanced Materials Research. Trans Tech Publ, pp. 2703-2707.

Sun, Y.Z., ShengHong; Wang,XiaoLing; Mei,ChuanShu, 2009. Multi-objeetive Optimization of regional water resourees based on mixed genetic algorithm. Systems Engineering-Theory \& Practice 29, 139-145.

Tang, L.L., ZiXi; Qi,YaRong, 2019. Comprehensive evaluation of urban water resources security in Ningxia au-tonomous region. Journal of Safety and Environment 19, 1810-1816.

Wang, H.C., QiuMi; Zhang,HaiTao; Guo,WenXian; Chen,DingXin; Wang,Qun, 2018. Research on the Water Source Bearing Capacity in Ninxia Based on Principle Component Analyses. China Rural Water and Hydropower, 30-34.

Wichelns, D., 2002. Economic analysis of water allocation policies regarding Nile River water in Egypt. Agricultural Water Management 52, 155-175.

Zhang, H.B., ShuPing, 2014. Water allocation and solutions for water use in Ningdong Energy and Chemical Industry Base. China Water Resources, 23-25.

Zhang, Y., 2010a. Comparative analysis of water rights transfer between East base of Ningxia and Zhang ye of Gansu. Law and economy, 46-47.

Zhang, Y., 2010b. Research on Optimal Allocation System of Water Resource. Journal of Yangtze River Scientific Research Institute 27, 6-11.

Zhao, C.L., Baohong; Cui,Dongmei; Deng,Shan; Mao,Dou; Wu,Xingxin; Xu,Kun, 2014. Study of Sustainable Utilization of Water Resources in NingXia Based on Ecological Footprint Theory. Water Resources and Power 32, 26-29.

Zhao, Z.L., WangCheng; Wang,Xia; Cui,TingTing; Cheng ZaiHeng; Wang, Shuai, 2017. Study on Water Resources Carrying Capacity in Ningxia Based on Principal Component Analysis and Factor Analysis. JOURNAL OF CHINA HYDROLOGY 37, 64-72.

Zilberman, D., Schoengold, K., 2005. The use of pricing and markets for water allocation. Canadian Water Resources Journal 30, 47-54. 